\title{
Autocracia. A psicopolítica do governo-de-si em Platão e Kant*
}

\section{Günter Zöller}

Professor na Ludwig-Maximilians-Universität em Munique

Tradução: Eveline Hauck

* A versão alemã deste ensaio apareceu sob o título de "Autokratie. Die Psycho-Politik der Selbstherrschaft bei Platon und Kant", publicado como parte do livro Kant als Bezugspunkt philosophischen Denkens, editado por H. Busche e A. Schmitt (Würzburg: Königshausen \& Neumann, 2010), p. 351-77. 

“E a expressão ‘senhor de si mesmo’ não é ridícula? Quem é mais forte que si mesmo também seria, claro, mais fraco que ele mesmo, pois é da mesma pessoa que se diz isso...”.

"Ele estava acostumado a chamar suas faculdades superior e inferior da alma de Casa Superior e Casa Inferior, e muito frequentemente a primeira lançava um aviso que a última rejeitava”².

Este artigo contrasta e compara a teoria do eu em Platão e em Kant, pelo exame, no trabalho de ambos os filósofos, do uso sistemático da conceitualidade política na estruturação do discurso ético. Enfatizaremos o complexo sistema do eu prático como palco de orientações e reivindicações concorrentes. A primeira metade do artigo explora a confiança platônica na constituição da cidade ideal como análoga à composição da alma na República. Daremos atenção especial à estrutura relacional da alma e a função de ligação da "impetuosidade" (thumós) na organização tripartite das funções básicas da alma. A segunda metade do artigo apresenta o esquema mais importante da teoria kantiana da maturidade a respeito da subjetividade prática, especialmente compreendida nos três amplos conjuntos de introduções de seu principal trabalho tardio em filosofia prática, A metafísica dos costumes 3 . A análise enfatiza conceitos-chave delineados pela filosofia política moderna que dão forma à compreensão e apresentação kantianas da estrutura relacional do eu prático, com especial atenção aos conceitos originalmente políticos de autonomia e autocracia. Nosso propósito, ao considerar a relação com o eu prático em Kant e Platão, não é fazer uma comparação substancial entre doutrinas políticas e éticas particulares, mas comparar funcionalmente, em ambos os filósofos, o papel formador do pensamento político para a noção de identidade. Platão e Kant emergem, cada

1 PLATÃO. A república, 430e-431-a. Trad. de A. L. A. de A. Prado. São Paulo: Martins Fontes, 2006, p. 151.

2 G. C. LICHTENBERG. Schriften und Briefe. 6 v. Munique. 1967-1992. Ed. de W. Promies.

3 I. KANT. Practical Philosophy. Trad. e ed. por M. J. Gregor. Intr. geral de A. Wood. Cambridge: Cambridge University Press, 1996, p. 370-85, 386-97 e 512-40. 
qual à sua maneira, como proponentes de uma filosofia prática abrangente que não separa teoria e prática da ética da teoria e da prática do direito e da política.

\section{A alma e a cidade}

As discussões filosóficas em torno da estrutura e da condição da identidade quase sempre enfatizam o eu cognitivo e concentram-se na forma e na função da autoconsciência teórica. O mesmo ocorre em muitos trabalhos de natureza e orientação histórica sobre o eu em Kant e em seus sucessores idealistas, especialmente Fichte e Hegel. Em particular, os trabalhos sobre a teoria kantiana da subjetividade normalmente enfocam a natureza da autoconsciência ou da apercepção transcendental não empírica e "pura", a distinção entre autoconsciência (Selbstbewu tsein) e autoconhecimento (Selbsterkenntnis) e a diferença entre eu noumenal e eu fenomenal. Por outro lado, comparativamente pouca atenção é dada à constituição da subjetividade prática em Kant. No entanto, muito da terminologia e conceitualidade que servem para demarcar e designar problemas da identidade na filosofia, incluindo aquelas que dizem respeito ao eu teórico, deriva da esfera das relações práticas humanas e de seu tratamento na filosofia prática. A linguagem que designa "atividade" (Tätigkeit), "ação" (Handlung) e "ato" (actus), delineada por Kant e seus sucessores para identificar e caracterizar a natureza do eu em geral e a natureza do eu teórico e cognitivo em particular, origina-se da esfera das relações práticas humanas. Em Fichte, a presença antecipada e em certo grau clandestina de características especificamente práticas da constituição genérica da subjetividade sempre se converte em uma total primazia da prática ${ }^{4}$.

4 Sobre os antecedentes kantianos da doutrina da primazia da prática de Fichte, veja-se: G. ZÖLLER. Am Anfang war... die Tat. Der Primat des Praktischen und das Faktum der reinen Vernunft in der Philosophie Kants. In: I. MÜLDER-BACH; E. SCHU- 
O uso de referências práticas no discurso kantiano e pós-kantiano acerca do eu não se limita, porém, a questões de linguagem e terminologia; ao contrário, isto demonstra e estrutura o completo desenvolvimento da identidade. Certamente, a preocupação central de grande parte da filosofia moderna de Descartes a Kant e em filósofos posteriores com relação a questões epistemológicas de certeza e objetividade conduziu a um enfoque predominante no eu como sujeito do conhecimento e objeto de reivindicações de conhecimento. O eu figura, contudo, também de maneira proeminente no pensamento legal, político e ético moderno, na condição de indivíduo e de sua relação com a sociedade civil e o Estado. Consequentemente, as formas abrangentes de considerar a identidade no período moderno tendem a tratar o eu em seu conjunto completo de funções 5 . Em particular, tais considerações do eu integral conferem proeminência às funções apetitivas, desiderativas ou volitivas da mente e julgam a cognição subordinada à volição e ao sentimento.

A integração da identidade teórica no contexto mais amplo da identidade prática original e primária pode servir de correção desejável à ênfase dada ao conhecimento e ao autoconhecimento em grande parte do pensamento moderno. Em particular, a reconsideração da natureza prática do eu une novamente o pensamento moderno sobre o eu à longa tradição da filosofia prática, que trata a alma (psuché, anima) ou a mente (noûs, mens) do eu como sujeito da ação e, também, como sujeito da ação racionalmente condicionada. Além disso, este movimento pode servir para lembrar-nos que os antecedentes, pré-modernos e da modernidade inicial, dos conceitos de identidade da alta modernidade não compartilhavam da preocupação posterior com questões

MACHER (Eds.). Am Anfang war... Ursprungsfiguren und Anfangskonstruktionen der Moderne. Munique : Fink, 2008, p. 91-105.

5 Veja-se, por exemplo: J. B. SCHNEEWIND. A invenção da autonomia. São Leopoldo (RS): Editora Unisinos, 2001. 
epistemológicas e com seu enfoque limitado ao eu individual. O eu prático - o eu da tradição da filosofia prática - é um eu social, preso a relações com outros seres e considerado em consonância com a natureza social do indivíduo.

Certamente, a condição secundária do eu individual e a primazia do eu social levam-nos de volta à compreensão clássica, pré-moderna, dos fatos e valores da vida humana, os quais sofreram revisão e crítica significativas no período moderno, em parte preparadas pelo ensinamento cristão do valor absoluto de cada ser humano. Consequentemente, os limitados conceitos de igualdade humana encontrados no mundo antigo - conceitos que ligam a igualdade não com a humanidade como tal, mas com uma condição social e civil - foram ampliados a fim de abarcar idealmente todos os seres humanos, a despeito de classe, raça ou gênero ${ }^{6}$. Além do mais, a básica convicção moderna acerca do valor incondicional, absoluto, do indivíduo humano - convicção com origens religiosas e consequências políticas - engendrou um cultivo da individualidade singular, pessoal, às custas da sociabilidade plural, interpessoal. A manifestação política dessa tendência modernista expressa-se no conceito individualista de liberdade como liberdade de escolha ou independência.

A moderna universalização da identidade para todos os seres humanos e sua particularização concomitante para cada ser humano permanecem, não obstante, ainda confinadas ao conceito de eu legado pela filosofia antiga. Em particular, a visão do eu como combinação de funções, capacidades e faculdades diferentes, ou mesmo divergentes, refere-se, como foi dito, à filosofia

$6 \mathrm{Um}$ documento essencial da historiografia moderna e progressista do pensamento moral e político é o curso público de Fichte de "filosofia aplicada" ("angewendete Philosophie") de 1813, conhecido por "Staatslehre" (doutrina do Estado), publicado postumamente. Veja-se: J. G. FICHTE. Gesamtausgabe der Bayerischen Akademie der Wissenschaften. Stuttgart: Frommann-Holzboog, 1962 e ss. Ed. de R. Lauth, H. Jacob; idem. Fichtes Sämtliche Werke. Berlim: W. de Gruyter, 1923, IV, p. 366-600. Ed. de I. H. Fichte (Berlim: Veit \& Camp, 1845). 
prática dos antigos e sua divisão da alma em diferentes "espécies" (eidé) específicas ou "gêneros" (géne), que fazem do eu - ou alma - o lugar de complexas distinções e inter-relações. Embora a natureza combinatória do eu seja também uma marca da legitimidade do eu teórico, particularmente quando este é visto decomposto em sentido perceptivo e pensamento (aisthesis e noesis), é principalmente o eu prático, em seus aspectos antigo e moderno, que apresenta a possibilidade ou a natureza verdadeiramente conflitante da identidade, no sentido em que põe a questão do eu ou da alma no palco de uma disputa interna quanto à influência e preponderância de funções opostas, como discernimento e desejo, cognição e volição, razão e inclinação.

O pensamento antigo sobre a complexa composição do eu, que permanece ainda em vigor, mesmo em suas transformações tardias, especificamente modernas, não concerne apenas à articulação interna do eu em suas funções, faculdades ou momentos constitutivos. O pensamento moderno sobre o eu é também ainda marcado pelas maneiras clássicas de apresentar e representar as formas dramáticas de interação dinâmica e completa entre os elementos constitutivos do eu. A herança antiga subjacente às considerações modernas da dinâmica da identidade privilegia a analogia psicopolítica entre a ordem da alma e da política. Em particular, a filosofia grega antiga prevê na constituição da alma e na relação de seus constituintes o modelo da cidade (pólis) e sua constituição interna (politeía). O principal exemplo da visão clássica da alma como a "cidade em nós" (pólis èn hemîn) é a República de Platão. A comparação estendida às ordens psíquica e política em Platão tem uma função cognitiva determinada explicitamente: a constituição macroscópica do corpo político justo serve para examinar a constituição microscópica da alma justa. Analisar a ordem política ampliada da cidade - tarefa que, para o observador filosófico, é comparativamente fácil - prova ser um meio indireto, mas efetivo de investigar a ordem da alma, cuja detecção é mais difícil. 
Mas a analogia platônica entre a alma e a cidade estende-se mais além da dimensão cognitiva de tratar a ordem política como lente de aumento da ordem psíquica. Também, e mais importante, a analogia transporta a dimensão normativa da filosofia política de Platão para a consideração interior da cidade, qual seja, a alma. Este movimento acarreta uma total politização da alma, pois os conceitos e estruturas especificamente políticos são utilizados na avaliação da alma. Transferindo a articulação e integração da cidade para a articulação e integração da alma, a República de Platão não apenas copia das classes da cidade a estruturação das faculdades da alma, ela também implica o discurso do poder (krátos) e da força (bía) na indagação concernente ao conhecimento e à sabedoria em questões éticas.

A analogia psicopolítica de Platão é de enorme significância histórica e sistemática. Em seu ponto principal, ela não é uma elucidação comparativa ulterior de entidades previamente identificadas e distinguidas. Antes de Platão, não havia ética filosófica como uma área de investigação separada e como um corpo de doutrinas que pudessem ser objeto de elucidação subsequente por meio de uma comparação com o pensamento filosófico sobre a cidade? . Valendo-se da cidade como modelo para a alma, tanto de maneira descritiva como prescritiva, Platão, com efeito, define a ética em termos de filosofia política e estabelece o curso do pensamento futuro sobre as estruturas e normas do eu ético.

A analogia psicopolítica platônica, porém, vai ainda mais longe: Platão não somente define uma disciplina emergente e completa, qual seja, a ética, em termos essencialmente políticos como pode ser igualmente considerado aquele que define ou, ao menos, redefine o próprio tema da ética como tal, por situar a alma no centro do pensamento ético e tratá-la como o núcleo

7 A obra ética contemporânea, escrita por Demócrito, está preservada apenas fragmentariamente. Veja-se: DEMÓCRITO. Fragmente zur Ethik. Trad. e coment. de G. Ibscher. Intr. de G. Damschen. Stuttgart: Reclam, 1996. 
complexamente composto da existência humana, a estrutura múltipla que é a base para a disputa interna - politicamente falando, para a guerra civil - entre forças competindo num único e mesmo ser. Em contraste marcante com a regulação externa da conduta humana, por meio da influência de poderes divinos e da operação das normas societais no pensamento grego precedente, Platão situa a fonte da conduta em cada ser humano e identifica a alma tanto como a fonte de demandas discordantes quanto como o lugar para seus confrontos e resoluções.

Ao passar de um governo heteronômico para um governo autonômico do eu, Platão dá continuidade à revolução ética de Sócrates, seu mestre, o qual havia descoberto que deliberação e decisão em matéria de conduta dependem de um princípio orientador da ação funcionando autonomamente na profundeza de nosso interior (daimónion). Entretanto, Platão vai mais longe que Sócrates na divisão e, portanto, na pluralização da alma, igualando sua estrutura e funcionamento à experiência humana tanto de oposição e disputa quanto de deliberação e decisão interiores. Visto sob esta perspectiva histórica, a atitude de Platão, quando lança mão de termos claramente políticos para capturar o sentido recentemente encontrado da identidade internamente conflituosa, tem de ser considerada como uma transformação de modos mais arcaicos, socialmente definidos, da identidade e como um passo importante na direção do estabelecimento de uma noção de identidade autodeterminada.

Fundando seu pensamento ético em características estruturais da vida na pólis, Platão articulou as descobertas (ou invenções) afins do eu interior e da ética filosófica a uma ordem política que substituiu tradições tribais comparativamente estáveis e regras convencionais de conduta por uma forma de regulação e governo sociais deliberadamente escolhidos e intencionalmente mantidos, que é por si mesma propensa ao conflito interior e à mudança autoinduzida. Considerando as afinidades estruturais e funcionais profundas entre a cidade grega e a alma em Platão, 
pode-se talvez assumir que aquela engendrou esta: a experiência da disputa política e sua resolução, ou mesmo a falta dela, conduz não tanto à descoberta, mas à completa invenção e formação de um modo de identidade, a constituição interna que se une intimamente àquela da vida circundante, ou, antes, da disputa, na pólis. O que de início deve ter parecido mera analogia empregada por Platão para ilustrar a natureza da alma por meio de sua comparação com a cidade acaba por atestar a origem comum do pensamento ético e político e, consequentemente, por apontar uma unidade mais profunda dos dois, os quais foram, subsequentemente, identificados como ação social humana (práxis) em Aristóteles. Apesar de apresentar ética e política separadas em seus escritos exotéricos, Aristóteles segue o precedente de Platão, de considerar a ética como parte da política e o governo da conduta humana uma questão essencialmente política ${ }^{8}$.

\section{A classe média da alma}

Em suas construções narrativas da cidade ideal, no diálogo platônico sobre a constituição política perfeita, Sócrates e seus interlocutores logo reconhecem a necessidade de um conjunto de soldados ou de uma classe cujo fim seja assegurar o território da pólis nascente9. A característica própria dos guardiões (phúlakes) é o "ardor" ou "impetuosidade" (thumós), que os faz destemidos e invencíveis. A classe dos guardiões diferencia-se, subsequentemente, em um grande número de "assistentes" (epíkouroi) e em um pequeno número de "governantes" (árkhontes), que comandam os demais. Assim, a cidade completa consiste em três classes ou estados, cada qual com tarefas especificamente diferentes na garantia da sobrevivência e prosperidade da pólis: de um lado, um

8 Veja-se: ARISTÓTELES. Nicomachean Ethics, 1093a-b, 1094b; e Politics, 1323a-b. 9 PLATÃO. República, op. cit., 373d-374d. 
grande número de camponeses (georgói) e artesãos (demiourgoí), de outro, um pequeno número de governantes e, entre os dois, os guardiões-assistentes.

No sentido de justificar e manter a organização política dos três estados, Sócrates - ou, mais propriamente, Platão - propõe que seja contada a todos, até mesmo aos governantes ${ }^{10}$, a "mentira nobre" (pseûdos gennâ̂os)" ou o "mito" (mûthos)", de acordo com as diferentes ligas inatas de metais em que cada classe diferente está fundamentada e que são fornecidas a cada uma delas pela deusa da forma. Diz-se que os governantes têm ouro, os guardiões-assistentes, prata, e o povo em geral ferro, adicionado a suas almas ${ }^{13}$.

No passo seguinte e principal de seu argumento, Sócrates (ou, mais propriamente, Platão) credita a possibilidade e realidade da cidade inteiramente boa à manutenção da sabedoria (sophía), da coragem (andreía) e da sobriedade (sophrosúne), assim como da justiça (dikaiosúne) ${ }^{14}$. Cada uma das três primeiras virtudes (aretaí) pode ser correlacionada com um dos três estados políticos. Em particular, a perfeição específica do governante é ser sábio no governo da pólis, a do guardião-assistente é ser corajoso na defesa da cidade e a do povo é ser sóbrio e moderado na busca de bens materiais. A virtude, porém, também se adapta à cidade como um todo e, além disso, a cada cidadão em particular na cidade, especialmente aos cidadãos livres (eleútheroi). Por último, a justiça é destacada como a virtude abrangente que assegura a boa ordem do curso da vida diária na cidade como um todo e em cada uma de suas classes constituintes. Na nova cidade (néa pólis) tão idealmente retratada, pode-se dizer que os melhores e mais fortes prevalecerão sobre os piores e mais fracos, de modo que a cidade

10 Veja-se: PLATÃO. República..., op. cit., 413b-c, d.

11 Id., ibid., 414b-c; veja-se também 382d, 389b.

12 Id., ibid., $415 \mathrm{a}$.

13 Id., ibid., 415 a-d.

14 Id., ibid., op. cit., 428a-434d. 
como um todo é o seu próprio senhor (kreîtton heautoû $)^{15}$.

Depois de estabelecer e tornar a cidade ideal habitada, a investigação desloca-se da pólis e dos seus três estados para todo e cada ser humano (hékaston tôn anthrópon), e, especificamente, da justiça política para a justiça do ser humano individual ${ }^{16}$. A diferenciação da pólis toda em três partes de naturezas diferentes (trittà gene phúseon) conduz Sócrates a supor, analogamente, que haja essas mesmas espécies (eíde) na alma dos seres humanos individuais (idiótai) ${ }^{17}$. Assim, a investigação move-se para a questão de haver ou não, na alma humana, essas mesmas três espécies. A presença destes três gêneros ou espécies é rapidamente estabelecida. Sócrates levanta a pergunta retórica: de onde mais poderiam ter advindo as três espécies e modos de conduta (eíde te kaì éthe) na pólis senão do fato de que já estavam presentes em seus membros constituintes ${ }^{18}$. Prosseguindo, Sócrates cita, como evidência da origem psíquica daquelas características políticas, a prevalência de um ou outro traço nas comunidades políticas, dependendo da inclinação prévia dos cidadãos. Os exemplos dados da etnopsicologia incluem a impetuosidade (thumoeidés) dos povos do norte, o amor ao saber (philomathés) dos gregos iônicos e a afinidade com o dinheiro (philokrhématon) dos fenícios e dos egípcios ${ }^{19}$.

Enquanto a presença dos três tipos na alma humana é comparativamente fácil de averiguar, é muito mais exigente e também urgente, segundo Sócrates, estabelecer se no exercício de cada um dos três diferentes modos de conduta a alma age como um todo (hóle he psukhé) ou apenas com uma das três características respectivas da alma. Essa questão aparentemente inofensiva e inconsequente é na realidade uma dúvida crucial sobre a natureza da alma - com potenciais consequências de grande alcance para

15 PLATÃO. República..., op. cit., 431b.

16 Id., ibid., 434d.

17 Id., ibid., 435b, 435d.

18 Id., ibid., $435 \mathrm{e}$.

19 Id., ibid., 435e-436a. 
sua condição posterior como uma entidade imaterial diferente do corpo e que não está sujeita ao posterior curso natural de crescimento e perecimento.

Notoriamente, o próprio Platão tentara estabelecer em outra parte, principalmente no Fédon, a imortalidade da alma com base em sua indivisibilidade, argumentando que o que é composto de partes pode, e realmente deve, desintegrar-se, enquanto a unidade verdadeira e simples é imune à mudança. Platão parece atento a essas considerações quando evita consistentemente a linguagem da parte e do todo para tratar a natureza complexamente estruturada da alma e, mais propriamente, lança mão da linguagem menos acometida mereologicamente de "gêneros" (géne) e "espécies" (eíde) para designar a articulação da alma. Um número razoável de tradutores de Platão tem sido menos zeloso em suas menções às "partes da alma”.

No sentido de averiguar se a alma é inteira ou constituída por apenas uma de suas características que está envolvida numa dada ação ou comportamento, Sócrates - ou, mais propriamente, Platão - lança mão do princípio de contradição, o qual lhe permite detectar diferenças naquilo que inicialmente pode parecer indiferenciado:

É evidente que o mesmo sujeito não poderá, ao mesmo tempo, fazer e sofrer coisas contrárias, pelo menos no mesmo sentido e em relação à mesma coisa. Sendo assim, se descobrirmos que isso se dá com aquelas qualidades, saberemos que não se trata da mesma qualidade, mas de muitas $^{20}$.

Em um primeiro passo da investigação, duas características da pólis interior, que é a alma, são distinguidas uma da outra, nomeadamente, os desejos (epithumíai) junto com anseio e vontade (ethélein, boúlesthai), constituindo a alma daquele que 
deseja (epithumoûntos psukhé), e aquilo que pensa na alma (logistikòn... tês psukhês $)^{21}$. Sócrates menciona circunstâncias em que alguém pode estar com fome ou sede e mesmo assim não se entregar ao seu desejo, argumentando que isto aponta uma presença dual na alma: há, portanto, algo que comanda o beber ou o comer e algo que evita que isso aconteça. O último é operativo por intermédio do pensamento (logismós) e o primeiro ocorre por intermédio de paixões (pathêmata) ou mesmo doença (nosémata) ${ }^{22}$.

Agora o argumento segue da seguinte maneira. Não podendo haver uma mesma coisa operando em direções opostas na mesma relação e ao mesmo tempo - de acordo com o princípio previamente aceito da (não-)contradição -, deve haver algo duplo (dittá) e diferente entre si (hétera), por meio do qual a alma pensa e por meio do qual a alma deseja ${ }^{23}$. A relação lógica de oposição entre aquilo que é desejoso (epithumetikón) e aquilo que pensa é também conduzida mediante a caracterização negativa do primeiro nos termos do segundo: desejoso é, também, aquilo que não pensa (alogistikón $)^{24}$.

Até agora duas espécies (dúo... eíde) 25 foram identificadas como inerentes à alma. Baseando-nos na analogia com a pólis, podemos esperar um terceiro gênero, o qual corresponderia à principal disposição dos guardiões-governantes. A questão que nos aparece é se a impetuosidade (thumós) é esta outra função elementar da alma e à qual as duas funções previamente distinguidas seriam similares (omophués) ${ }^{26}$. Um dos interlocutores supõe uma afinidade entre thumós e aquilo que é desejoso; Sócrates responde à questão recontando uma história destinada a demonstrar a sub-

21 PLATÃO. República..., op. cit., 437b-c e 439d.

22 Id., ibid., op. cit., $439 \mathrm{c}-\mathrm{d}$.

23 Id., ibid., 439d.

24 Id., ibid.

25 Id., ibid., 439e.

26 Id., ibid., 349e. 
missão do thumós, como terceira função intermediária da alma, à função do pensamento e sua oposição (tanto ético-política como lógica) à função do desejo:

Mas, disse eu, uma vez ouvi uma história a que dou fé. Ela diz que Leôncio, filho de Agalion, ao voltar do Pireu, passando ao longo do muro norte pelo lado de fora, percebeu cadáveres jazendo perto do lugar das execuções. Ao mesmo tempo, queria vê-los e deles se afastava e, por certo tempo, relutava e velava o rosto, mas, por fim, vencido pelo desejo, arregalando os olhos, correu em direção aos cadáveres e disse: "Eis aí, infelizes! Saciai-vos com o belo espetáculo" ${ }^{27}$.

A história como foi contada por Sócrates propõe um cenário demonstrando que o ardor (orgé) pode, às vezes, entrar em beligerância (polemeîn) com os desejos (epithumíai) ${ }^{28}$. Na revolta (stasiázein) dos desejos e na repreensão mútua, thumós opera como o aliado da razão. Sócrates e seus interlocutores também acreditam ter encontrado que thumós nunca tomará o partido do desejo contra a razão, senão quando corrompido por má educação (kakè trophé) $)^{29}$.

Não obstante, a diferença e mesmo oposição entre impetuosidade e desejo não estabelecem ainda a constituição tripartite da alma e sua correspondência composicional exata com a cidade. Para tal fim, deve-se mostrar que thumós é também funcionalmente diferente daquilo que é racional. De acordo com Sócrates, thumós, a despeito de todas as suas afinidades com o racional na alma, é especificamente diferente do que é racional na alma; consequentemente, os dois não podem ser considerados o mesmo. Como evidência de que thumós é especificamente diferente do racional, Sócrates menciona a presença de thumós em crianças que ainda não adquiriram razão, naqueles seres humanos que

27 PLATÃO. República..., 439e-440a, p. 165.

28 Id., ibid., 440a.

29 Id., ibid., op. cit., 440b e $441 \mathrm{a}$. 
nunca a adquirirão e mesmo nos animais, que são irracionais por natureza. Todos esses casos provam a diferença e mesmo a possível oposição entre a reflexão acerca do melhor e do pior (tò analogisámenon perì toû beltíonos te kaì kheíronos) e o ardor imprudente e irrefletido (tò alogístos thumoménon) 30.

Com o estabelecimento da constituição tripartite da alma, Sócrates e seus interlocutores prosseguem a fim de identificar a justiça no ser humano individual, segundo a analogia com a justiça na cidade. A justiça psíquica consiste, para o elemento racional da alma, em governar (árkhein) e cuidar da alma em sua totalidade; para o impetuoso, em ser subserviente ou obediente (hupékoos) e aliado (ksúmmakhos) $)^{31}$ e para o elemento apetitivo, em ser controlado pelos dois elementos anteriores de forma que se evite a subjugação dos outros dois por ele, perturbando a vida de todos $^{32}$. Em uma transferência direta da imagem política, Sócrates descreve a ocorrência da justiça, no que diz respeito à alma, como a disposição de seus elementos em uma relação natural de governo e subserviência mútua (katà phúsin... krateîn te kaì krateîsthai hup'allélon)33. Em contrapartida, a injustiça consiste na sublevação da ordem natural quase política da alma por meio da luta (tês psukhês stásis) e da revolta de uma parte (meros) ${ }^{34}$ contra o todo da alma35. Em tal beligerância interna e civil, as funções especificamente diferentes da alma tornam-se facções que combatem mutuamente pelo controle da alma desestabilizada.

30 PLATÃO. República..., op. cit., 441b-c.

31 Id., ibid., 441e.

32 Id., ibid., 442a-b.

33 Id., ibid., 444d-e.

34 É em uma circunstância narrativa que Platão emprega a designação partitiva na articulação da alma, "parte"; caso contrário, ele é atento no sentido de evitar a designação para descrever o estado deficiente, no qual um elemento da alma desprendeu-se de sua integração com o todo dela e conferiu a si mesmo independência.

35 Id., ibid., op. cit., 444a-b; veja-se também $440 e$ (psukhe stasis). 


\section{A autonomia da vontade}

Dirigir-se da psicopolítica normativa de Platão para a filosofia prática de Kant pode parecer um movimento completamente diferente e mesmo uma consideração filosófica oposta às relações que constituem o eu. Para começar, Platão não é a referência principal do pensamento kantiano sobre a constituição do eu prático (e também não o é Aristóteles). A referência clássica da ética de Kant é o estoicismo e, consequentemente, uma ética muito mais individualista que a integração da ética a um conceito essencialmente político e mais largo de valorização da vida humana que é encontrado em Platão (e em Aristóteles). A recepção kantiana da República de Platão parece ser limitada àquela última função reguladora e paradigmática de um "conceito de razão" (Vernunftbegriff) ou "ideia" (Idee), ou seja, uma "arquiimagem" (Urbild) infinitamente distante, porém tanto orientadora como motivadora, que o homem finito esforça-se para obter sem nunca atingir ${ }^{36}$. Com respeito às ideias práticas, como a "República platônica" (die platonische Republik), o esforço é em si prático ou uma questão da ação humana. Ao contrário, as ideias especulativas, principalmente aquelas da alma, do mundo como um todo e de Deus, são objetos de infinito esforço na aproximação cognitiva por meio da aquisição de conhecimento sempre mais extensivo e intensivo ${ }^{37}$. Além disso, a filosofia política e legal de Kant parece totalmente desconectada das considerações ideais e reais da vida na cidade que são encontradas em Platão (e Aristóteles). O contexto histórico da filosofia política e legal de Kant é o

36 Veja-se: I. KANT. Critique of Pure Reason, B 370-377/A 316-320.

37 A respeito da possível transmissão da teoria platônica das formas para Kant graças ao diálogo de Moses Mendelssohn Phädon oder über die Unsterblichkeit der Seele, veja-se: K. REICH. Kant und die Ethik der Griechen. Tübingen: Mohr, 1935. A respeito do significado geral das teorias filosóficas antigas para o desenvolvimento da filosofia crítica de Kant, veja-se: U. SANTOZKI. Die Bedeutung antiker Theorien für die Genese und Systematik Von Kants Philosophie. Eine Analyse der drei Kritiken. Berlim/ Nova York: Walter de Gruyter, 2006. 
Estado territorial soberano da era moderna, e seu motivo teórico são as considerações realistas e idealistas da natureza do Estado (statehood) em Maquiavel e Hobbes e em Locke e Rousseau e especialmente na moderna tradição do praeter-positive, da "lei natural" (Naturrecht) ou "lei da razão" (Vernunftrecht).

Mais importante, no centro da filosofia prática kantiana está um conceito de liberdade como capacidade absolutamente espontânea de ação interior e exterior, a qual é estranha ao mundo antigo em geral e, em particular, à perspectiva platônica (e aristotélica) do ser humano. Na filosofia grega e romana antigas, o pensamento e a ação humanos são considerados partes integrantes da ordem natural do mundo e consistem mesmo, em larga medida, em descobrir e considerar a ordem cósmica. Mesmo a maneira pela qual o filósofo entende as Formas de Platão, a vida de contemplação quase divina em Aristóteles ou a vida autosuficiente do sábio no estoicismo não parte da ordem natural, mas representa modos supremos de conformar-se a ela.

Em contrapartida, a filosofia prática de Kant funda-se em um conceito de liberdade como antinatureza. O pré-requisito para esta inversão radical na relação entre o ser humano e a natureza parte de um entendimento alterado da natureza e do lugar do ser humano nela. A revolução científica do período moderno inicial havia tomado o lugar da cosmologia teleológica dos antigos, principalmente aquela preservada e passada adiante pela Física de Aristóteles, com a imagem mecânica de um mundo composto de matéria e governado por leis universais que se ajustam à representação matemática. Filósofos modernos de Descartes, passando por Leibniz, até Kant contribuíram para as bases filosóficas da nova visão científica de mundo e empenharam-se em direcionar suas consequências e implicações a um entendimento especificamente moderno da existência humana. Quando Kant determina o mundo natural, constituído de objetos no espaço e no tempo e amparados por leis da natureza, como o domínio dos "fenômenos" (Erscheinungen), ele intencionalmente deixa vago o campo 
das coisas como elas são em si mesmas (Dinge an sich, Dinge an sich selbst). Enquanto totalmente inacessível à cognição teórica (Wissen) e constitutivamente limitado ao conhecimento (científico) de fenômenos espaçotemporais, o mundo inteligível ou noumenal (Noumena, mundus intelligibilis) fornecia um espaço conceitual para o mero pensamento - em oposição ao conhecimento determinado e intuitivamente assegurado - do não natural ou de seres livres e de suas interações dinâmicas em termos de substancialidade, causalidade e reciprocidade. Kant argumentou que o conceito racional de uma causa absolutamente incondicionada ou "liberdade cosmológica" (kosmologische Freiheit), que permaneceu como mera ideia reguladora na esfera da cognição teórica, assumiu uma realidade de si mesma como a ideia praticamente real - como "liberdade prática" (praktische Freiheit) - na esfera da atividade moral humana ${ }^{3}$.

Outra característica da reconceitualização radical de Kant da natureza e da liberdade, como consequência da revolução científica, é a correlação da liberdade supranatural recentemente estabelecida, que define o ser humano em oposição à determinação natural, com suas próprias leis, diferentes das leis da natureza consideradas pela filosofia natural moderna e descobertas por meio de experiências físicas. O caráter rigoroso das "leis da liberdade" (Gesetze der Freiheit) que acabam de ser encontradas ou descobertas assemelha-se à validade universal e necessária das leis da natureza. Na consideração kantiana, porém, as leis que governam a liberdade são diferentes das leis que governam a natureza, no sentido de que estas são infalível e automaticamente seguidas, enquanto aquelas são seguidas apenas de maneira contingente. Certamente, que as leis da liberdade sejam seguidas apenas de maneira contingente e de acordo com outras condições da parte

$3^{8}$ Veja-se: I. KANT. Critique of Pure Reason, A 532/B 560-A 537/B 565 e A 8o1e e ss./B $82 g$ e ess. 
dos seres que as seguem (seres humanos) é, para Kant, compatível com o estatuto incondicional destas leis absolutas como normas necessariamente válidas da conduta humana. As leis da liberdade têm validade mesmo que não sejam validadas. De fato, a diferença modal entre as leis da liberdade serem válidas rigorosa e necessariamente e serem seguidas apenas de maneira contingente é indicativo da complexa constituição do eu prático na filosofia moral kantiana da maturidade.

Kant, como anteriormente Platão, vale-se da conceitualidade política para delinear e caracterizar as qualidades específicas da estrutura do eu prático. Enquanto a consideração platônica do ser humano interior recorre à cidade, sendo esta um ser humano em grande proporção (makroánthropos), a teoria kantiana da subjetividade prática é concebida sob a influência formativa do pensamento político moderno. Em particular, Kant delineia a constituição do eu prático e sua relação com as leis da liberdade nos termos dos poderes políticos que constituem o Estado moderno e nos termos da procedência e eficácia de suas leis. $\mathrm{Na}$ consideração kantiana, o eu prático está para as leis da liberdade em uma dupla relação, que pode ser expressa como a distinção jurídico-política entre estabelecimento (giving-out) e manutenção (carrying-on) das leis, em outras palavras, da legislação e da execução. A distinção remete à análise influente de Montesquieu sobre a origem e função das leis políticas em relação aos poderes (pouvoirs) que constituem o estado em O espírito das leis ${ }^{39}$. As reflexões historicamente conhecidas de Montesquieu sobre as inter-relações formativas entre direito e política foram, subsequentemente, remodeladas em uma consideração normativa da origem

39 Veja-se: MONTESQUIEU. De l'esprit des lois. 2 v. Paris: Garnier, 1973, v. 1, p. 168 (Livro XI, Capítulo VI). Ed. de R. Derathé. Aqui, Montesquieu caracteriza a jurisdição como um tipo de poder executivo, nomeadamente, como o poder executivo com referência a questões que dependem do direito civil (droit civil), em oposição ao poder executivo com referência a questões que dependem do direito público (droit des gens). 
contratual e do exercício quase democrático do poder do Estado no Contrato social de Rousseau, no qual as autoridades legislativa e executiva (puissance législative, puissance exécutive) foram distinguidas e relacionadas mutuamente com vontade (volonté) e poder (pouvoir) ${ }^{40}$.

Kant, recorrendo a Rousseau, separa, no eu individual - mais precisamente no eu individual prático -, o soberano, que dá a lei, do súdito, que deve segui-la. Na teoria rousseauniana da soberania popular, o mesmo corpo político que tem o poder de promulgar leis, nomeadamente, o povo, é também o corpo político ao qual elas são endereçadas. Kant segue a filosofia política de Rousseau na identificação da capacidade envolvida no ato de legislação. Em Rousseau, ela é a vontade, mais precisamente, a vontade legislativa ou "vontade geral" (volonté générale)4+. Em Kant, as leis práticas são promulgadas pela vontade, mais precisamente, pela "vontade pura" (reiner Wille) 4². $^{2}$

Kant igualmente transporta, do discurso político para a filosofia moral, o termo "autonomia" (Autonomie), a fim de designar a soberania da vontade que dá a lei (lawgiving will)43; além de manter o sentido impessoal e institucional do termo. Na filosofia prática de Kant, a autonomia, no sentido rigoroso e técnico de autoridade legislativa independente, não se refere ao eu prático como tal, mas apenas o faz como faculdade de promulgação de lei (lawgiving), em contradição com aquelas funções, capacidades ou faculdades devido às quais a autopromulgação de leis está - ou não - sendo seguida. Consequentemente, a vontade, em sua capacidade legislativa de vontade pura - vontade moralmente pura e puramente moral -, estrita e propriamente falando, não é

40 Veja-se: J.-J. ROUSSEAU. Du contract social. Paris: Garnier-Flammarion, 1966, p.

97 (Livro III, Capítulo I). Ed. de P. Burgelin.

41 Id., ibid., p. 54 (Livro I, Cap. VII), p. 67 e ss. (Livro II, Cap. I).

42 I. KANT. Practical Philosophy..., op. cit., p. 46, e também p. 164.

43 Id., ibid., p. 89. 
livre; porém, ela também não é sem liberdadet4. Antes, ela deve ser considerada como a fonte das leis da liberdade ou daquelas leis que governam o livre exercício das capacidades práticas e das capacidades do eu.

Portanto, Kant diferencia a "vontade" (Wille) da "faculdade de escolha" (Willkür) executiva, e, das duas, apenas a última pode ser considerada livre em seres como nós (seres humanos), os quais são suscetíveis de conduta racional e de base racional no âmbito da escolha deliberativa ${ }^{45}$. Diferentemente, seres finitos não racionais ou brutos podem operar com base na escolha entre instintos ou impulsos concorrentes. A escolha é, porém, internamente exigida - pelas leis da natureza - e não envolve a "faculdade de livre escolha" (freie Willkür) ${ }^{46}$. Ademais, seres como nós, capazes de livre escolha, não são apenas aptos a escolher livremente sua conduta com base no raciocínio prático - ou raciocínio sobre razões em geral -, mas também são capazes de agir especificamente com base apenas nas leis da liberdade, sem a ajuda de considerações e razões ulteriores. Kant representa a suscetibilidade de seres racionais finitos para a ação não somente com base em razões de todos os tipos, mas, específica e exclusivamente, com base tão só na razão, "razão prática pura" (reine praktische Vernunft)47. Além disso, no modo quase político pelo qual Kant considera a questão, a razão pura prática é tanto a autoridade legislativa quanto a autoridade executiva no estabelecimento das leis da liberdade.

$\mathrm{O}$ aspecto fundamental subjacente às leis múltiplas da liberdade defendido por Kant é a legitimidade da razão pura prática como tal, que se baseia em uma forma absoluta de universalidade. $\mathrm{Na}$ subordinação do exercício livre da vontade a uma ordem de conduta, as leis da liberdade substituem a liberdade "selvagem"

44 I. KANT. Practical Philosophy..., op. cit., p. 380.

45 Id., ibid., p. 375,380 e ss.

46 Id., ibid., p. 375; idem. Critique of Pure Reason..., op. cit., A 801 e ss./B 829 e ss.

47 Idem. Practical Philosophy..., op. cit., p. 45; e também p. 139, 164. 
por uma "liberdade ordenada" (geordnete Freiheit) $4^{8}$. Kant emprega o termo tradicional "costumes" (Sitten) - correspondente ao termo latino mores (costumes) - para designar o caráter ordenado da conduta humana. Mas a forma plural tomada da tradição não deve ser considerada como indicativa de uma pluralidade perfeita de normas regulando a conduta humana conforme tempo e lugar. Mais propriamente, Kant une as regras plurais de conduta sob a conceitualização de uma "lei da moral" (Sittengesetz) ou "lei moral" (moralisches Gesetz) singular e original ${ }^{49}$.

A pluralidade de leis da liberdade identificadas por Kant não é, então, manifestação de uma conceitualização pluralista de morais concorrentes, mas resulta da especificação ulterior da "lei da moral" singular que postula a forma da universalidade racional como tal em termos de leis de conduta plurais e de conteúdo específico. Além disso, o conteúdo e, consequentemente, a pluralidade das leis morais não têm origem na razão prática pura per se, que é essencialmente limitada à apresentação e imposição de forma meramente racional (universalidade) para princípios de conduta possíveis e reais que podem ter sua origem fora e independentemente da razão propriamente dita. Kant denomina "máximas" tais princípios de conduta que governam a conduta dos indivíduos antes da lei da moral suprema e formal, recorrendo ao termo tradicional para regras de conduta maximamente abrangentes $^{50}$. Estritamente falando, a autonomia da vontade, concebida por Kant de acordo com as linhas políticas de legislação no Estado, é, então, limitada ao metaprincípio de que a conduta, em conformidade com as máximas, tem de ser suscetível de adotar

48 I. KANT. Reflexionen zur Moralphilosophie, n. 7202. In: idem. Kant's gesammelte Schriften. Berlim: Preussischen und Deutschen Akademie der Wissenschaft, 1902, v. 19, p. 276 . Veja-se também: W. KERSTING. Wohlgeordnete Freiheit. Immanuel Kants Rechts- und Staatsphilosophie. Frankfurt am Main: Klostermann, 1993.

49 Idem. Practical Philosophy..., op. cit., p. 171, 173.

50 Id., ibid., p. 144 nota, p. 373-6; idem. The Critique of Judgement. Trad. de J. C. Meredith. Oxford: Clarendon, 1988, p. 16. 
a forma de legislação universal. A conduta moral, embora individualmente determinada por máximas dadas, deve satisfazer a condição formal mínima de que as máximas dadas podem ser o objeto da legislação universal.

Tendo concebido a origem e a condição da lei moral em termos de instituição política da legislação do Estado, Kant dá prosseguimento à caracterização da condição da lei moral com respeito ao ser humano por meio de outra característica da teoria e prática da política moderna, o sistema bicameral de legislação, no qual diferentes grupos cooperam e competem no delineamento e na transmissão das leis. Kant vê o eu prático como constituído de dois modos de base diferentes para a determinação de sua conduta. A genérica "faculdade de desejar" (Begehrungsvermögen), por meio da qual as "representações" (Vorstellungen) operam como fundamentos para a ação, é dividida em faculdade de desejar "inferior" e "superior" (unteres Begehrungsvermögen, oberes Begehrungsvermögen $)^{51}$. Enquanto a faculdade de desejar superior é suscetível de fundamentos para a ação puramente racionais, a faculdade de desejar inferior tem seus fundamentos para a ação estipulados por fatores não racionais e sensíveis.

Considerando o fato de que, em seres práticos e racionais como nós (humanos), os fundamentos sensíveis para a ação não constituem, por si mesmos, razão suficiente para a ação, mas são sujeitos à aprovação - ou desaprovação - da "faculdade de livre escolha” (freier Willkür), os fundamentos determinantes da faculdade de desejar inferior são considerados "inclinações" (Neigungen). Sua influência inclina, sem necessidade, o eu prático. A "faculdade de escolha" (Willkür) pode ser denominada "livre", desde que seja independente de compulsão interna por predominância de desejos. Ademais, mesmo que tais desejos não precisem da faculdade de escolha, ainda assim eles a influenciam e "afetam" 
(affizieren) e, por este meio, podem fazê-la recusar a lei moral.

Assim como a faculdade de livre escolha não é necessariamente determinada por desejos, ela também não segue necessariamente a lei moral. Para ser capaz de vigorar sob inclinações concorrentes, como o fundamento determinante e suficiente da vontade, a lei moral, enquanto resultado da vontade legisladora, tem que se apresentar ao ser racional finito como adesão impositiva e imposição incondicionada. A lei moral aparece sob a guisa quase política de uma ordem executiva instruindo o eu prático a segui-la sob todas as circunstâncias. A universalidade possível das máximas encerrada pela lei moral assume, portanto, a forma exterior do imperativo categórico para, assim, agir naquelas máximas e somente naquelas que estão sujeitas à legislação universal5².

Kant explica a diferença intensional entre a lei moral e o imperativo categórico em termos extensionais: a lei moral vigora para todos os seres práticos racionais e finitos, incluindo seres como nós (humanos), mas também para seres moralmente perfeitos, caso haja algum; enquanto o imperativo categórico diz respeito somente àqueles seres práticos racionais que estão sujeitos a inclinações contrárias às exigências da lei moral, e que, por este motivo, estão inclinados, embora não compelidos, a não segui-la.

Dado o caráter de comando incondicional que a lei moral adquire diante de uma racionalidade prática finita e sensorialmente afetada, o imperativo categórico não apenas opera como princípio para a cognição da conduta do ser humano (principium dijudicationis), ele também opera como princípio de recognição, ou reconhecimento, de tal comportamento e serve para motivar a execução da lei moral (principium executionis) ${ }^{53}$. Em sentido modal, a "necessidade" (Notwendigkeit) da lei moral assume ulte1963 , p. 36. 
riormente o caráter de "compulsão" (Nötigung)54, representando o que é praticamente necessário, mas que pode não ocorrer devido a inclinações de compensação e de prevalência, como exigido e comandado pela lei moral ou em conformidade com o "dever" (Pflicht $)^{55}$.

\section{A autocracia do eu}

Na República de Platão, aquilo que mais tarde vem a ser terminologicamente diferente, como ética (ethikê) e ciência política (politikê), encontrou um tratamento unitário, atestando o caráter inteiramente político da ética no pensamento clássico antigo, antes da despolitização e da privatização da ética na Grécia helenística, assim como na Roma republicana e imperial. Mesmo Aristóteles, que introduziu a distinção disciplinar da filosofia prática em ética, política e economia, trata a ética como parte integral de um estudo compreensivamente concebido de questões políticas e conduz a Ética Nicomaqueia para um campo mais vasto de noções políticas ${ }^{56}$. A conceitualização unitária da filosofia prática em Platão (e Aristóteles) encontra uma continuação modificada tardiamente em Kant, para quem "filosofia prática" (praktische Philosophie) coincide com "filosofia moral" (Moralphilosophie), com exclusão da economia e de outros campos do conhecimento técnico, que atribuem ao uso prático a cognição teórica sem contar com princípios genuinamente práticos, os quais devem envolver leis da liberdade em vez de leis da natureza57.

Rememorando a divisão antiga da filosofia prática em ética e política, Kant separa “direito" (Recht) e "ética" (Ethik), estabelecendo-as como as duas partes da filosofia prática. De modo

54 I. KANT. Practical Philosophy..., op. cit., p. 165.

55 Id., ibid., p. 52, 55 .

56 ARISTÓTELES. Nicomachean Ethics, 1180a-1181b.

57 I. KANT. The Critique of Judgement..., op. cit., p. 8. 
diferente de Platão e Aristóteles, os quais limitaram o conhecimento a priori aos objetos naturais e sobrenaturais da filosofia teórica (tà phusiká, tà metà tà phusiká), Kant, porém, mantém a suscetibilidade, e mesmo a necessidade, da filosofia prática para especificar-se um corpo de conhecimento prático não empírico ${ }^{5}$. Este adquire a forma de princípios a priori da lei e da ética ou da "metafísica dos costumes em duas partes" (Die Metaphysik der Sitten in zwei Teilen), quais sejam, os "Primeiros princípios metafísicos da doutrina do direito" (Metaphysische Anfangsgründe der Rechtslehre) e os "Primeiros princípios metafísicos da doutrina da virtude" (Metaphysische Anfangsgründe de Tugendlehre)59.

A unidade da filosofia prática, e especificamente dessa metafísica da moral, em duas partes, é assegurada pelo funcionamento do imperativo categórico como princípio supremo, tanto da lei como da ética. Uma característica genérica ulterior da filosofia prática, não obstante a diferença entre lei e ética, é sua preocupação com uma "legislação" (Gesetzgebung) ${ }^{60}$ que envolva leis da liberdade ou leis que tornem possível a realização da liberdade. A diferença específica entre legislação jurídica e ética vige graças a distinções semelhantes às distinções entre "ações internas" e "externas" (innere, äu ere Handlungen ${ }^{61}$ e entre a legislação que faz apenas da ação um dever e a legislação que, além de fazer da ação um dever, também a faz ser um dever, uma força motivadora ("incentivo", Triebfeder), para a ação. A primeira legislação, a qual se abstém de preceitos motivacionais, é jurídica e envolve todas e apenas aquelas obrigações ("deveres”, Pflichten) que podem ser externamente legisladas, por uma ou mais pessoas ou por uma instituição que imponha sua vontade legisladora a outros, que são normalmente os súditos de uma comunidade ou estado político.

61 Id., ibid. 
Em contrapartida, a legislação que não pode ser externa e que não envolve a imposição da vontade de outrem é ética (ethisch $)^{62}$.

Valendo-se da conceitualização da vontade legislativa e executiva para toda a esfera das leis práticas, com inclusão específica das leis éticas da liberdade, Kant estende o uso dos conceitos jurídico-políticos às camadas mais profundas da ética. Na verdade, os conceitos jurídicos e políticos originais sofrem modificações específicas quando levados da lei para a ética. Eles retêm, contudo, traços bastantes de sua significação anterior ou subjacente para introduzir um elemento jurídico-político básico no discurso ético kantiano da segunda parte da Metafísica dos costumes.

O mais importante é que Kant toma a noção jurídico-política de "coerção" (Zwang) - e especificamente a "coerção [...] da faculdade de livre escolha por meio da lei" (Zwang [...] der freien Willkür durchs Gesetz) - do direito e da política e a aplica à éti$\mathrm{ca}^{63}$. O termo serve mais amplamente para caracterizar genericamente a obrigação moral que envolve um "constrangimento" (Nötigung), já que esse termo jurídico-político é introduzido para designar medidas legais e políticas tomadas com o intuito de assegurar a efetividade da legislação. Na esfera do direito e da política, o traço comum, genérico, da legislação prática, nomeadamente a coação da livre escolha com base na lei e governada pela lei, ocorre como "coerção externa" (äu erer Zwang) ou "coerção por outrem" (Zwang durch einem Anderen) ${ }^{64}$.

Em contrapartida, a coerção implicada na esfera da ética é interna. Ela não implica outrem no exercício da coerção. A coerção ética é "autocoerção" (Selbstzwang) ${ }^{65}$. Mais precisamente, a coerção peculiar para a obrigação ética ou o dever ético é "autocoerção livre" (freier Selbstzwang) ${ }^{66}$, em oposição à autocoerção

62 I. KANT. Practical Philosophy..., op. cit., p. 383-5.

63 Id., ibid., op. cit., p. 512 (tradução modificada).

64 Id., ibid., p. 512, 526 e 525 (tradução modificada).

65 Id., ibid., p. 512 e ss., 525 e ss.

66 Id., ibid., p. 515, 525. 
sem liberdade implicada na faculdade de livre escolha quando coagida pela lei da natureza. Isto ocorre quando uma "inclinação natural" (Naturneigung) ${ }^{67}$ esforça-se para coagir outra. Em contraste, no caso da autocoerção livre, a coerção na faculdade de livre escolha não é exercida por inclinações concorrentes, mas pela "razão prática pura" como poder da vontade legislativa que é capaz de coagir a influência de inclinações internas ${ }^{68}$.

A autocoerção ética, porém, não é apenas negativamente livre no que diz respeito à ausência de inclinações com bases naturais; ela pode ser igualmente considerada livre no sentido positivo, na medida em que ela é exercida de acordo com as leis da liberdade, que servem para constatar a liberdade coletivamente por meio de restrição distributiva. No caso paradigmático de coerção externa exercida por leis jurídicas de liberdade, a coação legal torna possível uma "liberdade exterior" (äu ere Freiheit) $)^{69}$ pela limitação da liberdade de todos mediante o conceito de liberdade de todos os outros. No caso análogo de coerção interna exercida em si mesmo, a coerção exercida pelas leis éticas restitui uma possível "liberdade interna" (innere Freiheit) ${ }^{70}$ pela limitação da influência de inclinações mediante o conceito de autonomia da vontade. Com base na consideração geral de que a completa possibilidade de liberdade intersubjetiva (jurídica) ou intrassubjetiva (ética) requer coerção por meio de leis que auferem a liberdade por meio da sua restrição, Kant avalia a magnitude intensional da liberdade em termos do tipo de coerção de lei envolvida e determinada: “Autocoerção é o máximo grau de liberdade [...]”71.

Kant assinala a diferença entre a genérica "autonomia da ra-

67 I. KANT. Practical Philosophy..., op. cit., p. 525.

68 Id., ibid., p. 526.

69 Id., ibid., p. 513,526 e 534 .

70 Id., ibid., p. 526,533 e ss., 536.

71 I. KANT. Idem. Kant's gesammelte..., op. cit., p. 28, 1; p. 100 (Metaphysik Herder):

"Der Selstzwang ist der höchste Grad der Freiheit [...]". 
zão prática" (Autonomie der praktischen Vernunft) ${ }^{72}$, que detém completamente o domínio da filosofia prática, na medida em que a razão é o fundamento de validade das leis da liberdade, e a legislação específica envolvida na ética por meio do recurso à "autocracia" (Autokratie) ${ }^{73}$, termo de inflexão política, para assinalá-la. No regime autocrático da ética, a legislação autônoma das leis éticas condiz com a consciência da habilidade ou faculdade (Vermögen) do indivíduo para prevalecer sobre aquelas inclinações que são opostas à lei. Kant não afirma que se tenha uma percepção imediata desta faculdade ou habilidade como tal, mas estabelece a consciência mediada, inferida, dela na percepção imediata do imperativo categórico ético ${ }^{74}$.

Valendo-se da autocracia, conceito originalmente político, Kant escolhe um termo que carrega, em um e mesmo ser, a unidade do poder legislativo e executivo. Como o próprio Kant formula: na autocoerção livre da obrigação ética e dos deveres éticos, a razão legislativa "constitui-se como um poder de execução de lei" (sich zu einer das Gesetz ausführenden Gewalt selbst constituirt) ${ }^{75}$. Kant designa a autocapacidade autocrática da vontade legisladora de executar a vontade em assuntos éticos com o termo tradicional "virtude" (Tugend), por causa da "força moral da vontade" (moralische Stärke des Willens $)^{76}$. Ele continua a usar conceitos do sistema político para a constituição do eu ético quando identifica a virtude com o comando "de unir todas as suas faculdades e inclinações sob o seu poder (racional)" (seine Vermögen und Neigungen unter seine [der Vermunft] Gewalt zu bringen) ou o "governo de si” (Herrschaft über sich selbst)77. Em particular, Kant mencio-

72 I. KANT. Practical Philosophy..., op. cit., p. 515.

73 Id., ibid.

74 Id., ibid.

75 Id., ibid., p. 533 (tradução modificada; ênfase em itálico no original na palavra "ausführenden").

76 Id., ibid.

77 Id., ibid., op. cit., p. 536 (tradução modificada). 
na uma dupla exigência para a autocracia ética: a primeira, com respeito aos "afetos" (Affekten), que constituem possíveis desvios da obrigação moral e dos deveres éticos pelo sentimento - deve-se ser "senhor de si mesmo" (seiner selbst [...] Meister) -, e a segunda com respeito às "paixões" (Leidenschaften), que constituem possíveis desvios da obrigação moral e dos deveres éticos pelos desejos - deve-se ser "comandante de si mesmo" (über sich selbst Herr zu sein $)^{78}$. Apoiando-se a analogia política envolvida, pode-se acrescentar que o propósito da automestria e do autocomando em assuntos éticos não é a extirpação dos afetos e dos desejos, mas seu domínio - assim como o propósito da regra política não é, de acordo com o pensamento político clássico, abolir o que é comandado, mas o seu controle.

De acordo com Kant, a autocoerção envolvida na conduta ética exibe uma característica ulterior que atesta a natureza particularmente conflitante do eu prático; primeiramente, há a autocoerção livre exercida pela razão prática pura ou vontade pura sobre a faculdade de livre escolha, almejando sobrepujar a inclinação que lhe é contrária. Devido à persistente "resistência de sua inclinação" (Widerstand ihrer Neigung), os seres humanos, mesmo quando seguindo a "lei moral" (moralisches Gesetz), o fazem com “relutância” (ungern)79. É por essa razão que há necessidade de ser-se coagido, em primeiro lugar, por parte da vontade legisladora. Na avaliação de Kant, porém, há também uma coerção, em direção oposta, envolvida na conduta ética - uma coerção que não é exercida contra inclinações resistentes à coerção ética ou à autocoerção livre, mas em defesa da determinação puramente ética da vontade contra aquelas inclinações que seriam capazes de vigorar sob a autocoerção ética livre ${ }^{80}$.

78 I. KANT. Practical Philosophy..., op. cit., p. 535 (tradução modificada; as palavras

"Meister" e "Herr" enfatizadas no original).

79 Id., ibid., p. 512 e ss., nota na p. 512 (tradução modificada; ênfase no original).

80 Id., ibid., veja-se nota na p. 512. 
A resistência com a qual os seres humanos obedecem aos comandos da lei moral, se eles o fazem, tem sua contraparte exata na resistência com que eles desobedecem àqueles simples comandos, se eles o fazem. De acordo com Kant, a transgressão ética não ocorre de maneira triunfante ou mesmo contente e fora de uma completa convicção, mas de forma resistente e envolve tanto percepção quanto compreensão do erro cometido. Consequentemente, o eu prático está enredado em dois tipos de coerção que são necessários internamente e, portanto, representam tipos diferentes de autocoerção. Ademais, as duas formas de autocoerção são opostas entre si, pois operam na "faculdade de livre escolha" (Willkür) em direções opostas: uma coage a resistência por parte das inclinações, que não querem aquiescer à lei, a outra coage a prevalência das inclinações em sua não aquiescência à lei.

Kant caracteriza a posição peculiar da duplicidade relutante do eu prático - um eu que é eticamente relutante e também não eticamente relutante - como uma "autocoerção mutuamente oposta" (wechselseitig entgegengesetzte[r] Selbstzwang) e reconhece o eu internamente conflitante na "encruzilhada" (Scheideweg[e]) entre "virtude e voluptuosidade" (Tugend und Wohllust $^{8_{1}}$. Enquanto estruturalmente semelhantes, a autocoerção livre e a autocoerção sem liberdade ${ }^{8_{2}}$, em sua reciprocidade oposicional que constitui a condição humana, são funcionalmente assimétricas e não se cancelam simplesmente em uma relação equipolente. Kant menciona um "fenômeno" (Phänomen): o ser humano, na encruzilhada, mostra ser "mais propenso a escutar a inclinação do que a lei” (mehr Hang [...] der Neigung als dem Gesetz zu geben $)^{8}$. Aqui, Kant refere-se a um fato antropológico, que ele considera confirmado empiricamente, mas não suscetível de explicação. Qualquer explicação do fenômeno da antimora- 
lidade envolveria sua derivação de uma causa em conformidade com a lei da natureza. Tal explicação naturalista estaria, porém, em desacordo com a liberdade, assumida ou pressuposta, de nossa "faculdade de escolha" (Willkür), uma suposição ou pressuposição feita em bases estritamente morais e independentemente da evidência factual do prevalecimento da imoralidade.

Como na pólis platônica de um só homem em íntimo conflito, a república de íntima luta de Kant enfrenta a ameaça da contradição e da autodestruição lógica. Ademais, como Platão, Kant lança mão de uma distinção interna do eu que lhe permite determinar as formas opostas de autocoerções, que o eu tanto exercita quanto suporta como funções especificamente diferentes da subjetividade prática. Em particular, Kant atribui a resistência na obediência da lei moral à condição dos seres humanos de "seres de natureza racional" (vernünftige Naturwesen), os quais subordinam sua racionalidade a desejos extrarracionais, ou mesmo irracionais ${ }^{8}$. Em contrapartida, ele determina a relutância na desobediência da lei moral à condição dos seres humanos de "seres morais" (moralische Wesen). Nesta última qualidade, o ser humano não está sujeito às leis naturais e deve ser considerado - e deve considerar a si mesmo - um "ser (moral) livre" (freies [moralisches] Wesen): livre de coerção tanto de natureza interna quanto externa e livre para suportar a autocoerção racional com base na "sua humanidade de pessoa" (Menschheit in seiner eigenen Person $)^{85}$. O termo "humanidade" deve ser considerado aqui não só de maneira extensional, com inclusão de todos os seres humanos, mas também de maneira intensional, no sentido de excluir aqueles traços dos seres hu-

\footnotetext{
84 Sobre a diferença entre um "ser racional" (vernünftiges Wesen) e um "ser de razão" (Vernunftwesen), veja-se: id., ibid., p. 544 (tradução modificada; ênfase na palavra "Naturwesen" no original).

85 I. KANT. Pratical Philosophy..., p. 512 e ss., nota na p. 512. Veja-se nessa obra também a distinção referida entre "homo noumenon" e "homo phaenomenon" nas p. 544, 547 (ênfase nas palavras "freies" e "Menschheit" no original).
} 
manos que impedem a "animalidade do próprio ser humano" (Thierheit des Menschen) ${ }^{86}$.

Kant amplia ainda mais a composição dual do eu prático pela comparação entre o "animal humano" (Thiermensch) e o "ser humano racional" (Vernunftmensch) ${ }^{87}$. Naquela, o ser humano não é apenas um animal, mas um "animal dotado de razão" (mit Vernunft begabtes Thier), capacitado à conduta com instrução racional ${ }^{88}$; e nesta o ser humano é um "ser racional" (vernünftiges Wesen), capacitado à conduta determinada exclusiva e completamente pela razão ${ }^{89}$.

Assim como Platão, Kant resiste a dissolver a constituição complexa e conflituosa do eu na coexistência compatível de partes distintas em um todo fechado. Termos tais como "humanidade" e "animalidade", juntamente com cunhagens tais como "ser humano como ser animal" e "ser humano como ser racional" manifestam um esforço de diferenciação do eu (prático). Alinhado com esta compreensão, Kant não considera a presença da animalidade no ser humano um caso de inclusão parcial, mas se vale da locução preposicional pouco usual "o animal junto ao ser humano” ([das] Thier [es] am Menschen) ${ }^{90}$.

Em vez de dividir o ser humano, Kant empreende uma diferenciação funcional ao atribuir a este, com respeito à prática, uma “personalidade de duas partes" (zweifache Persönlichkeit) ${ }^{91}$.

De acordo com Kant, o ser humano idêntico numericamente ("numero idem") opera de uma maneira duplicada e até certo ponto diferente em espécie ("specie diversus"), nomeada-

86 I. KANT. Pratical Philosophy..., op. cit., p. 545. (tradução modificada; ênfase na palavra "Thierheit" no original).

87 Id., ibid., p. 557 (as palavras "Thiermensch" e "Vermunftmensch" estão enfatizadas no original).

88 Id., ibid., p. 575.

89 Id., ibid.

90 Id., ibid., p. 566 (tradução modificada; minha ênfase na locução "junto ao" e na palavra "am").

91 Id., ibid., p. 560 e ss. e nota (tradução modificada). 
mente, como um "objeto da legislação moral que se origina no conceito de liberdade" (Subjekt der moralischen, Von dem Begriffe der Freiheit ausgehenden Gesetzgebung) e como um "ser humano sensível dotado de razão" (der mit Vermunft begabte Sinnenmensch $)^{92}$. A diferença específica no funcionamento da subjetividade prática humana é atribuível às "faculdades do ser humano (tanto as superiores quanto as inferiores)" (der Fakultäten des Menschen [der oberen und unteren]) 93. Pensando o conceito de ser humano "não em um e mesmo sentido" (nicht in einem und demselben Sinn), mas de forma a envolver um sentido dual de subjetividade, Kant une sua filosofia moral, em particular sua ética, com a "diferenciação das coisas como objetos de experiência daquelas mesmas coisas tomadas como coisas em si" (Unterscheidung der Dinge, als Gegenstände der Erfahrung, von eben denselben, als Dingen an sich selbst) ${ }^{94}$, tratada na Crítica da razão pura. A "distinção crítica" (kristische Unterscheidung)95 faz do reaparecimento prático uma distinção, com respeito a um e mesmo ser humano, entre o ser humano internamente livre ("homo noumenon") e o ser humano tanto determinado de maneira causal quanto determinante ("homo phaenomenon") ${ }^{96}$. Como em Platão, a filosofia prática em Kant vale-se da filosofia primeira, da mesma forma que, em Platão e Kant, a ética vale-se da política e do direito.

92 I. KANT. Pratical Philosophy... (tradução modificada).

93 Id., ibid. (tradução modificada).

94 Idem. Critique of Pure Reason..., op. cit., BXXVII.

95 Id., ibid., BXXVIII.

96 Idem. Pratical Philosophy..., op. cit., p. 544. 


\section{Bibliografia}

ARISTÓTELES. Nicomachean Ethics. . Politics.

DEMÓCRITO. Fragmente zur Ethik. Trad. e coment. de G. Ibscher. Intr. de G. Damschen. Stuttgart: Reclam, 1996.

FICHTE, J. G. Fichtes Sämtliche Werke. Berlim: W. de Gruyter, 1923. Ed. de I. H. Fichte (Berlim: Veit \& Camp, 1845).

. Gesamtausgabe der Bayerischen Akademie der Wissenschaften. Stuttgart: Frommann-Holzboog, 1962 e ss. Ed. de R. Lauth, H. Jacob.

KANT, I. Lectures on Ethics. Trad. de L. Infield. Indianapolis (In)/Cambridge: Hackett, 1963.

. The Critique of Judgement. Trad. de J. C. Meredith. Oxford: Clarendon: 1988.

. Practical Philosophy. Trad. e ed. por M. J. Gregor. Intr. geral de A. Wood. Cambridge: Cambridge University Press, 1996.

. Critique of Pure Reason.

. Kant's gesammelte Schriften. Berlim: Preussischen und Deutschen Akademie der Wissenschaft, 1902.

KERSTING, W. Wohlgeordete Freiheit. Immanuel Kants Rechtsund Staatsphilosophie. Frankfurt am Main: Klostermann, 1993.

LiCHTENBERG, G. C. Schriften und Briefe. 6 v. Munique, 1967-1992. Ed. de W. Promies.

MONTESQUIEU. De l'esprit des lois. 2 v. Paris: Garnier, 1973, v. 1. Ed. de R. Derathé.

PLATÃO. A república. Trad. de A. L. A. de A. Prado. São Paulo: Martins Fontes, 2006.

REICH, K. Kant und die Ethik der Griechen. Tübingen: Mohr, 1935.

ROUSSEAU, J.-J. Du contract social. Paris: Garnier-Flammarion, 1966. Ed. de P. Burgelin. 
SANTOZKI, U. Die Bedeutung antiker Theorien für die Genese und Systematik Von Kants Philosophie. Eine Analyse der drei Kritiken. Berlim/Nova York: Walter de Gruyter, 2006.

SCHNEEWIND, J. B. A invenção da autonomia. São Leopoldo (RS): Editora Unisinos, 2001.

ZÖLLER, G. Am Anfang war... die Tat. Der Primat des Praktischen und das Faktum der reinen Vernunft in der Philosophie Kants. In: MÜLDER-BACH, I.; SCHUMACHER, E. (Eds.). Am Anfang war... Ursprungsfiguren und Anfangskonstruktionen der Moderne. Munique: Fink, 2008.

Autokratie. Die Psycho-Politik der Selbstherrschaft bei Platon und Kant. In: BUSCHE, H.; SCHMITT, A. (Eds.). Kant als Bezugspunkt philosophischen Denkens. Würzburg: Königshausen \& Neumann, 2010. 
